\title{
Insights on the Amino Acid Side-chain Interactions of a Synthetic T-cell Doterminant
}

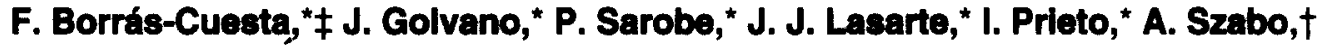 \\ J. L. Guillaumet and J. G. Guillet $\dagger$ \\ *Departamento de Medicina Interna, Facultad de Medicina, Universidad de Navarra, Pamplona, \\ Spain and +Laboratoire d'Immunopharmacologie moléculaire, Institut de Génétique moléculaire, \\ Hopital Cochin, Paris, France
}

\begin{abstract}
The effect of single amino acid substitutions at positions 18 and 20 on the T-cell determinant (TD) character of peptide p12-26 from lambda repressor protein and on its recognition by a monoclonal antibody was studied by means of 40 synthetic peptides of a length of 15 amino acids. ELISA competition experiments showed that the identity of amino acid at position 20 is very important for antibody recognition, whereas that of amino acid at position 18 is much less important. In contrast, both Leu 18 and Ala 20 are important residues in defining the TD character of peptide p12-26. The most tolerated replacements, ordered in increasing disrupting power are: Ala 20 by Cys, Ser or Gly and Leu 18 by lle or Val. Any other amino acid replacement completely abolishes the TD capacity of peptide p12-26. The peptides used in this study were synthesized using a multiple solid-phase peptide synthesizer newly designed. Their purity was very high as shown by amino acid sequence experiments.
\end{abstract}

\section{Introduction}

Synthetic peptides have proved to be very useful to study applied and theoretical aspects of Immunology. Thus, peptides have been synthesized: (i) to detect antibodies in the sera: ${ }^{1-3}$ (ii) to confer immunogenicity to a peptide hapten by linking this hapten to an amino acid sequence recognized by $\mathrm{T}$ cells; $;^{4-9}$ and (iii) to block protein-protein interactions, for instance, the one between the gp 120 envelope protein of HIV-1 and the CD4 receptor of T lymphocytes. ${ }^{10,11}$

Because T-cell determinants are immunogenic per $s e$, they are a convenient model to study two central aspects of immunology. That is, antigen-antibody and (T-cell determinant)-MHC-TCR interactions. We illustrate below the effect of amino acid substitutions on the sequence of LEDARRLKAIYEKKK (A TD from lambda repressor protein ${ }^{12}$ from now on referred to as p12-26) in monoclonal antibody and Tcell hybridoma recognition of this TD.

\section{Materials and methods}

Peptide synthesis

Peptides were synthesized by the solid-phase method of Merrifield ${ }^{13}$ using the Fmoc alternative. ${ }^{14}$

$\ddagger$ To whom correspondence should be addressed.
The synthesis was carried out using a new multiple synthesis apparatus (patent pending) designed by one of us (F. Borrás-Cuesta). This apparatus allows the simultaneous synthesis of 96 peptides of different sequence in quantities of 3 to $5 \mathrm{mg}$. Because the synthesis is carried out in independent reactors, resin samples from any reactor can be taken out if required to monitor coupling efficiency using the ninhydrin test of Kaiser. ${ }^{15}$

\section{Peptide sequencing}

To test the purity of the synthetic peptides, four of them chosen at random were sequenced without previous purification. Peptide sequencing was performed on a 470A automated protein sequencer (Applied Biosystems, Foster City, California). PTHderivatives of amino acids were analysed by an online 120A PTH-analyser HPLC (Applied Biosystems, Foster City, California). Slightly modified PTH standard cycles of Edman degradation were used. This modification is the replacement of the aqueous TFA delivery at the beginning of the cycle by an aqueous acetonitrile delivery. This modification allows a decrease in the formation of dehydro-derivatives of serine and threonine residues, together with an increase of the peak intensity of true serine and threonine PTH-residues. Our experience had shown that cystein by-product formation through beta- 
elimination is practically not affected. The unambiguous identification of cysteine residues is therefore possible with the peptide amounts used for sequencing. All peptides were sequenced on glassfiber filters impregnated with polybrene as a carrier. ${ }^{16}$

\section{Cell cultures and assay conditions}

All cultures and assays were performed in RPMI containing $10 \%$ fetal calf serum (FCS) (both from Boehringer Mannheim, F.R.G.), $10 \mathrm{~mm}$ glutamine, penicillin $(100 \mathrm{U} / \mathrm{ml})$, streptomycin $(100 \mu \mathrm{g} / \mathrm{ml})$, and $2 \times 10^{-5}$ M 2-mercaptoethanol (complete medium).

\section{Cells lines}

TA3 (I-A $\left.{ }^{\mathrm{d} / \mathrm{k}}, \mathrm{I}-\mathrm{E}^{\mathrm{d} / \mathrm{k}}\right)$ was a gift of Dr L. Glimcher, and 9C127 T-cell hybridomas were obtained by polyethylene glycol-mediated fusion of antigen primed lymph node T-cells to the AKR-derived thymoma BW 5147 as described. ${ }^{12}$ CTLL.2, an IL-2dependent T-cell line was a gift of $\mathrm{Dr} D$. Raulet. B3-11B cell hybridomas which secreted monoclonal antibodies specific for peptide p12-26, were obtained from Dr Ming-Zong Lai.

\section{Stimulation of $T$ cell hybridoma}

For reactivity pattern, $5 \times 10^{4} \mathrm{~T}$ hybridoma cells and $5 \times 10^{4}$ TA3 presenting cells were cultured in duplicate in 96-well, flat-bottomed microtiter plates in complete medium. Serial dilutions of the appropriate peptide were plated in a final volume of 0.2 $\mathrm{ml}$. Cultures were incubated for 18 to $24 \mathrm{~h}$ and $50 \mu \mathrm{l}$ of supernatants were harvested and frozen for more than $2 \mathrm{~h}$ at $70^{\circ} \mathrm{C}$. Aliquots of $5 \times 10^{3}$ to $1 \times 10^{4}$ CTTL.2, were added to warmed supernatants. Tritiated thymidine ( $1 \mu \mathrm{Ci} /$ well) was added 18 to 24 $\mathrm{h}$ later; the cells were harvested $6 \mathrm{~h}$ later by an automated cell harvester (Skatron Inc., Sterling, Virginia, U.S.A.). Incorporated thymidine was detected by scintillation counting (beta-Plate system from LKB, Uppsala, Sweden).

\section{ELISA competition assays}

Nunc (Denmark) microtiter plates were coated with solution of $2 \mu \mathrm{g} / \mathrm{ml} \mathrm{BSA}$-(p12-26) conjugate in 0.1 $\mathrm{M} \mathrm{Na}_{2} \mathrm{CO}_{3}$, for $1 \mathrm{~h}$ at room temperature. After saturation of the wells with $\mathrm{PBS}$ supplemented with $1 \%$ skimmed milk powder and $0.1 \%$ Tween-20, serial dilutions of the appropriate peptide were added and monoclonal antibody from hybridomas B3-11 culture supernatant was allowed to adsorb on the peptide for $1 \mathrm{~h}$ at room temperature. The mouse antibodies were revealed by successive $1 \mathrm{~h}$ room temperature incu- bations with rabbit biotinylated anti-mouse IgG antibodies (Immuno Research Laboratories, West Grove, Pennsylvania), diluted 1:1000 in saturation buffer and a streptavidin-peroxydase conjugate (Sigma Chemical Co., St Louis, Missouri), at a 1:1000 dilution in the same buffer. After washing the wells in PBS, $\mathrm{H}_{2} \mathrm{O}_{2}$-ABTS (Boehringer Mannheim, F.R.G.) substrate was added and the optical density (OD) was measured at $405 \mathrm{~nm}$ in a Titertek Multiscan MKII (Flow Laboratories, Irvine, Ayrshire, U.K.) ELISA reader. Results were expressed as the peptide concentration giving $50 \%$ inhibition of the recognition of BSA-p12-26 conjugate by the monoclonal antibody $\mathrm{B} 3-11$.

\section{Results and discussion}

We synthesized the peptide LEDARRLKATYEKKK (encompassing amino acids 12-26 of lambda repressor protein), and 38 analogs corresponding to all amino acid changes in positions 18 and 20 of this sequence. To test the purity of these peptides we randomly chose four of them for sequencing. These were the wild type LEDARRLKAIYEKK and the analogs LEEDARRIKAIYEKKK, LEDARRMKAIYEKKK and LEDARRQKAIYEKK. Direct sequencing, without HPLC purification of these peptides allowed the unambiguous identification of all residues. Secondary sequences were not visible at high peptide concentration, showing the high degree of completion of the coupling reactions. These results proved that the purity of the peptides tested was better than $95 \%$ (data not shown).

The 38 synthetic analogs were used to study the effect on stimulation of proliferation of a T-cell hybridoma, and also, on monoclonal antibody recognition of an antibody induced with the wild type peptide.

Effect of amino acid substitutions at positions 18 and 20 of $p 12-26$ on $T$-cell proliferation

In Table 1 we show the effect of amino acid substitutions on the stimulation of proliferation of an I-A ${ }^{d}$ restricted T-cell hybridoma. The best proliferation is obtained by the wild type peptide which has a Leu at position 18. Moderate proliferation of the Tcell hybridoma can be induced if Leu is substituted by the conservative amino acids Ile and Val. However, these substitutions require more than a 40-fold increase in the concentration of the modified peptides to attain a proliferation curve where the maximum tritium uptake is $15000 \mathrm{cpm}$ in compari- 
Table 1. Effect of amino acid substitutions at positions 18 and 20 of peptide p12-26 on the stimulation of proliferation of an I-A $A^{d}$ restricted T-cell hybridoma

AA at position 18 of modified peptide

Peptide conc. $(\mu \mathrm{g} / \mathrm{ml})$ giving $50 \%$ prolif stimulation

\begin{tabular}{lc}
\hline L (wild type) & $6 \dagger$ \\
I & $250 \ddagger$ \\
V & $250 \ddagger$ \\
A,C,D,E,F,G,H,K,M & $*$ \\
N,P,Q,R,S,T,W,Y & $*$ \\
AA at position 20 & \\
of modified peptide & \\
\hline
\end{tabular}

\begin{tabular}{lc}
\hline A (wild type) & $6 \dagger$ \\
C & $30 \S$ \\
S & $140 \dddot{I}$ \\
G & $250 \ddagger$ \\
D,E,F,H,I,K,L,M & $*$ \\
N,P,Q,R,T,V,W,Y & $*$ \\
\hline
\end{tabular}

* A peptide concentration of $1000 \mu \mathrm{g} / \mathrm{ml}$ did not induce proliferation.

The 50\% proliferation stimulation was calculated from titration curves where the maximum tritium uptake was: (†) $100000 \mathrm{cpm}$; (†) 15000 ; (\$) 80000 ; (प) $70000 \mathrm{cpm}$.

son with $100000 \mathrm{cpm}$ when using the unmodified peptide.

Amino acid substitutions in position 20 show that the least disrupting effect on proliferation is obtained when replacing Ala 20 by Cys and by Ser.
These changes require a five-fold and a 25 -fold increase in peptide concentration respectively to attain proliferaton curves having maxima of $80000 \mathrm{cpm}$ and $70000 \mathrm{cpm}$ in comparison to 100000 when using the unmodified peptide. If $\mathrm{Ala}$ is changed by Gly, over a 40 -fold excess is required to attain a maximum of $15000 \mathrm{cpm}$. Any of the possible remaining amino acid substitutions destroy the ability of the peptide to stimulate the proliferation of the T-cell hybridoma.

These results show that Leu 18 and Ala 20 are important residues in defining the T-cell determinant character of peptide p12-26. In particular, Leu 18 can not be replaced without dramatic changes in the induction of T-cell hybridoma proliferation.

\section{Effect of amino acid changes at positions 18 and 20 of p12-16 on monoclonal antibody recognition}

Figure 1(a) shows the inhibition of binding of monoclonal antibody B3-II to a BSA-(p12-26) conjugate adsorbed on microtiter wells. This inhibition was carried out using synthetic peptides modified at position 18 . The bars representing the different modified peptides have been arbitrarily ordered (from left to right) according to increasing inhibition. When a low concentration of peptide is required it means that this peptide is well recognized by B3-II. On the contrary, if a high concentration is necessary, the peptide is poorly recognized by the antibody.

Replacing Leu at position 18 by Gln, Ile, Lys, Met, Asn, Val or Arg, does not alter antibody recognition
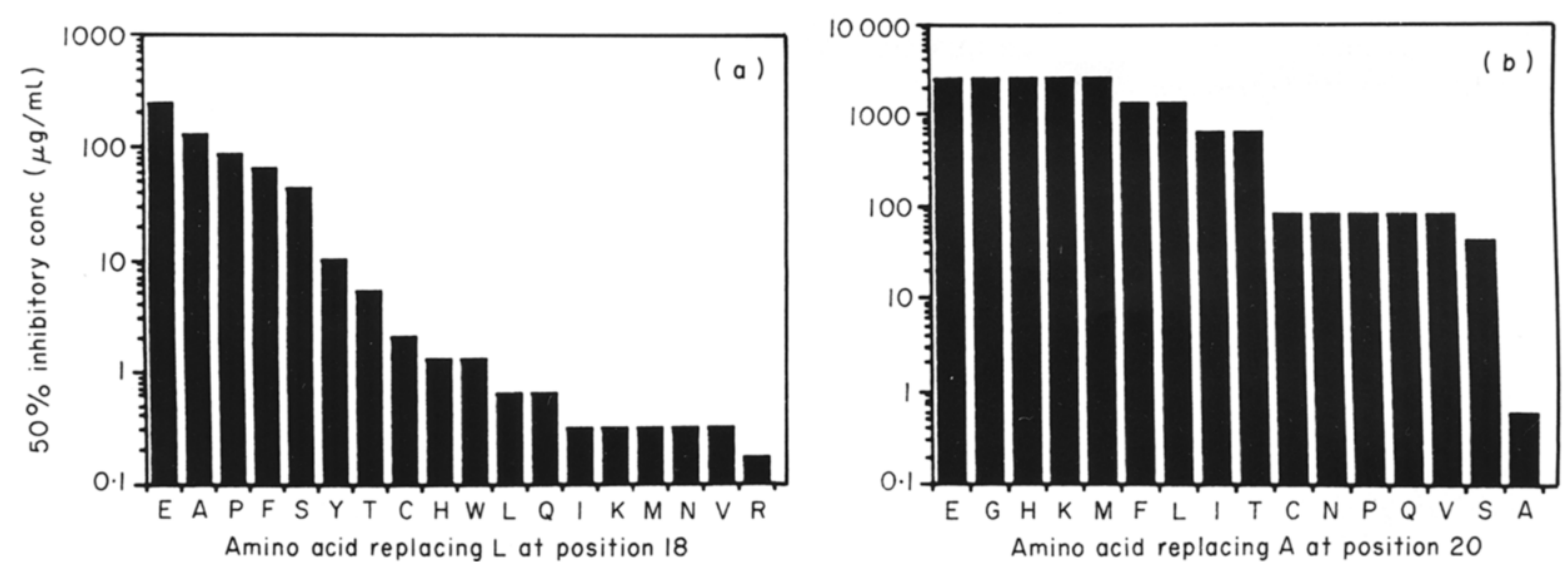

Figure 1. Inhibition of the binding of B3-II monoclonal antibody to BSA-(p12-26) conjugate by synthetic peptides. These peptides are modifications of peptide p12-26 at one of the two positions: Leu 18 or Ala 20. Inhibition is expressed as the peptide concentration giving $50 \%$ binding inhibition. Each bar corresponds to a modified peptide identified by a single letter corresponding to that of the amino acid at the modified position. The absence of a bar indicates that binding inhibition could not be reached even with $5000 \mu \mathrm{g} / \mathrm{ml}$ of $\mathrm{mod}$ ified peptide. (a) Effect of amino acid replacement at position Leu 18. (b) Effect of amino acid replacement at position Ala 20. 
of BSA-(p12-26) conjugate, whereas replacement by Asp or Gly is responsible for the most pronounced decrease. Replacing by Glu, Ala, Pro, Phe, Ser, Tyr, Thr, Cys, His and Trp has an important to moderate effect in the amino acid order given. The decrease in antibody recognition induced by Asp and Glu might be associated with a repulsion effect between the carboxyl side-chains of Asp or Glu of the modified peptides and similar side-chains of the antibody. The effect of Gly and Pro (amino acids which are well known for their capacity to induce turns in peptides and proteins) might be associated with conformational changes induced by them on the peptides.

Amino acid substitutions at position 20 have a much more pronounced effect on the recognition of B3-II than those at position 18 [compare Fig. 1(a) with Fig. 1(b)]. The least disrupting changes induced after replacement of amino acid 20 are those observed for Ser, Val, Gln, Pro, Asn and Cys. However, replacing Ala 20 by Ser (which is the least disrupting change) requires a 60 -fold excess in peptide concentration respect to that of unmodified peptide to attain the same degree of antibody inhibition. Other amino acid replacements require even higher concentrations of modified peptide. In particular, replacement by Asp, Arg, Trp or Tyr cannot inhibit antibody recognition even using an 8000 -fold excess of modified peptide. To summarize, although the identity of the amino acid at position 20 is very important for antibody recognition, that of at position 18 is not.

More experiments are being carried out to characterize further the role of the other amino acid residues of LEDARRLKATYEKKK not only with respect to their interaction with the monoclonal antibody but also with respect to their effect on the stimulation of proliferation of the T-cell hybridoma.

We believe that in view of the relative low cost of multiple solid phase peptide synthesis, the experimental use of synthetic peptides to map potential B and T-cell determinants within proteins is a safer strategy than mapping these determinants by means of theoretical algorithms. ${ }^{17-24}$

\section{References}

1. Geysen HM, Barteling SJ, Meloen RH. Proc Natl Acad Sci USA 1985; 82: 178-182.

2. Geysen HM. Immunol Today 1985; 6: 364-369.

3. Gnann WJ, McCormick BJ, Sheila M, Nelson AJ, Oldstone BAM. Science 1987; 237: 1346-1349.

4. Good MF, Malloy WL, Lunde MN, Margalit $H$, Cornette JL, Smith GL, Moss B, Miller LH, Berzofsky JA. Science $1987 ; 235$ : 1059-1062.

5. Leclerc C, Przewlocki G, Chutze MP, Chedid L. Eur J Immunol 1987; 17: 269-273.

6. Borrás-Cuesta F, Petit-Camurdan A, Fedon Y. Eur J Immunol 1987; 17: 1213-1215.

7. Borrás-Cuesta F, Fedon Y, Petit-Camurdan A. Eur J Immunol 1988; 18: 199-202.

8. Francis MJ, Hastings GZ, Syred AD, McGinn B, Brown F, Rowlands DJ. Nature 1987; 330: 168-170.

9. Golvano JJ, Lasarte JJ, Sarobe P, Gullón A, Prieto J, Borrás-Cuesta F. Eur J Immunol 1990; 20: 2363-2366.

10. Lifson JD, Hwang KM, Nara PL, Fraser B, Padget M, Dunlop NM, Eiden LE. Science 1988; 241: 712-716.

11. Nara PL, Hwang KM, Rausch DM, Lifson JD, Eiden LE. Proc Natl Acad Sci USA 1989; 86: 7139-7143.

12. Guillet J-G, Ming-Zong Lai, Briner TJ, Smith JA, Gefter ML. Nature 1986; 324: 260-262.

13. Merrifield RB. J Am Chem Soc 1963; 85: 2149-2154.

14. Atherton E, Logan JC, Sheppard CR. J Chem Soc Perkin Trans 1981; 1: 538-546.

15. Kaiser E, Colescott RL, Bossinger CD, Cooke PI. Anal Biochem. 1970; 34: 595-598.

16. Tarr GE, Beecher JF, Bell M, McKean D. Anal Biochem 1978; 84: 622-627.

17. Hopp TP, Woods KR. Proc Natl Acad Sci USA 1981; 78: 3824-3828.

18. Kyte J, Doolittle R. J Mol Biol 1982; 157: 105-132.

19. Karplus PA, Schulz GE. Naturwissenchaften 1985; 72: 212-213.

20. Welling GW, Weijer WJ, van der Zee R, WellingWester S. FEBS Lett 1985; 188: 215-218.

21. Rose GD, Geselowitz AR, Lesser GJ, Lee RH, Zehfus MH. Science 1985; 229: 834-838.

22. Parker JMR, Guo D, Hodges RS. Biochem 1986; 25: 5425-5432.

23. Margalit H, Spouge JL, Cornette JL, Cease KB, Kemp B, DeLisi C, Berzofsky JA. J Immunol 1987; 138: 2213-2229.

24. Rothbard JB, Taylor WR. EMBO J, 1988; 7: 93-100.

25. Stille CJ, Thomas LJ, Reyes VE, Humphreys RE. Mol Immunol 1987; 24: 1021-1027.

Received for publication 5 November 1990; accepted 18 March 1991. 